\title{
Prenatal Stress Enhances Responsiveness to Cocaine
}

\author{
Tod E Kippin*, ${ }^{*, 2}$, Karen K Szumlinski ${ }^{1,2}$, Zuzana Kapasova', Betsy Rezner' and Ronald E See ${ }^{2}$ \\ 'Department of Psychology, The Neuroscience Research Institute, University of California, Santa Barbara, CA, USA; ${ }^{2}$ Department of \\ Neurosciences, Medical University of South Carolina, Charleston, SC, USA
}

\begin{abstract}
Early environmental events have profound influences on a wide range of adult behavior. In the current study, we assessed the influence of maternal stress during gestation on psychostimulant and neurochemical responsiveness to cocaine, cocaine self-administration, and reinstatement of cocaine-seeking in adult offspring. Pregnant, female Sprague-Dawley rats were subjected to either no treatment or to restraint stress three times per day for the last 7 days of gestation and cocaine-related behavior was assessed in offspring at 10 weeks of age. Relative to controls, a noncontingent cocaine injection elevated locomotor activity as well as nucleus accumbens levels of extracellular dopamine and glutamate to a greater extent in both cocaine-naïve and cocaine-experienced prenatal stress (PNS) rats and elevated prefrontal cortex dopamine in cocaine-experienced PNS rats. To assess the impact of PNS on cocaine addiction-related behavior, rats were trained to lever press for intravenous (i.v.) infusions of cocaine $(0.25,0.5$, or I mg/ $\mathrm{kg} /$ infusion), with each infusion paired with a light + tone-conditioned stimulus. Lever-pressing was extinguished and cocaine-seeking reinstated by re-exposure to the conditioned cues or by intraperitoneal cocaine-priming injections ( 5 or $10 \mathrm{mg} / \mathrm{kg}$ ). PNS elevated active lever responding both during extinction and cocaine-primed reinstatement, but not during self-administration or conditioned-cued reinstatement. PNS also did not alter intake during self-administration. These findings demonstrate that PNS produces enduring nervous system alterations that increase the psychomotor stimulant, motivational, and neurochemical responsiveness to noncontingent cocaine. Thus, early environmental factors contribute to an individual's initial responsiveness to cocaine and propensity to relapse to cocaine-seeking. Neuropsychopharmacology (2008) 33, 769-782; doi:I 0. I038/sj.npp. I 30I447; published online 9 May 2007
\end{abstract}

Keywords: prenatal stress; cocaine; self-administration; reinstatement; dopamine; glutamate

\section{INTRODUCTION}

Environmental stimuli during the embryonic period have profound effects on developmental processes, resulting in permanent alterations in nervous system structure and function. In humans, children of mothers that experienced stress during gestation show alterations in early motor development, anomalies in brain morphology, and increased risk of developing a range of behavioral abnormalities such as attention-deficit hyperactivity disorder, sleep disturbances, cognitive dysfunction, increased anxiety, and substance-abuse disorders (reviewed in Huizink et al, 2004; Seckl and Meaney, 2006; Weinstock, 2001, 2005). Extensive data from animal studies are consistent with such findings (reviewed in Huizink et al, 2004; Kofman, 2002; Seckl and Meaney, 2006; Weinstock, 2001, 2005; Welberg and Seckl, 2001); repeated maternal exposure to stress during the last week of gestation induces behavioral sequelae including (but not limited to) increased anxiety, learning and memory

*Correspondence: Dr TE Kippin, Department of Psychology, The Neuroscience Research Institute, University of California, Santa Barbara, CA 93106-9660, USA, Tel: + I 805893 2459, Fax: + I 805893 4303, E-mail: kippin@psych.ucsb.edu

Received 3 January 2007; revised 3 April 2007; accepted 4 April 2007 impairments, altered circadian rhythm function, and impaired sexual function. Thus, remarkable parallels exist between human and animal models of the behavioral and neurological consequences resulting from stressful experience during development.

The role of gestational stress in addiction vulnerability has received limited empirical attention. Offspring of rat mothers exposed to repeated maternal restraint stress during the last week of gestation and allowed to lever press for amphetamine as adults displayed an approximate fourfold increase in intake (Deminiere et al, 1992). Moreover, rats exposed to the same treatment regimen also exhibit increased locomotor activity during exposure to amphetamine (Deminiere et al, 1992; Henry et al, 1995) and facilitated amphetamine-induced sensitization of locomotor activity (Henry et al, 1995). Similarly, exogenous administration of corticosterone during late gestation enhances locomotor responses to amphetamine (Diaz et al, 1995). However, no studies have investigated the influence of maternal stress exposure during gestation on relapse vulnerability or on the responsiveness to other abused psychostimulant drugs.

Accordingly, the present report provides the first investigation of the influence of maternal stress during gestation on the behavioral and neurochemical responsive- 
ness to cocaine in the rat. Specifically, we determined the effects of repeated maternal restraint stress during the last week of gestation-hereafter referred to as prenatal stress (PNS) - on the locomotor activity induced by a novel environment or noncontingent cocaine exposure in drugnaïve subjects, the acquisition and maintenance of cocaine self-administration under operant control, and the reinstatement of cocaine-seeking by cocaine-paired cues or by cocaine-priming injections. Mesocorticolimbic dopamine and glutamate, particularly in the prefrontal cortex (PFC) and nucleus accumbens (NAC), have been widely implicated in the neurobiology of cocaine addiction (for reviews see Anderson and Pierce, 2005; Di Chiara et al, 2004; Kalivas et al, 2005). In particular, it has been argued that dopamine neurotransmission in the PFC controls NAC glutamate, which is critical for reinstatement of cocaine-seeking behavior (Capriles et al, 2003; McFarland et al, 2003, 2004; Sun and Rebec, 2005). To examine potential neurobiological correlates to behavioral alterations produced by PNS, we also examined cocaine-induced changes in extracellular neurotransmitter levels in the PFC and NAC in both PNS and control rats with or without cocaine selfadministration experience.

\section{MATERIALS AND METHODS}

\section{Subjects}

Male ( $n=8$, weighing $275-300 \mathrm{~g}$ at the start of the experiment) and female ( $n=16$, weighing $250-275 \mathrm{~g}$ at the start of the experiment) Sprague-Dawley rats (CharlesRiver) were individually housed in a temperature- and humidity-controlled vivarium on a 12-h light-dark cycle. Rats were maintained on ad libitum water and rat chow (Harlan, Indianapolis, IN). The housing and care of the rats followed the guidelines of the 'Guide for the Care and Use of Laboratory Rats' (Institute of Laboratory Animal Resources on Life Sciences, National Research Council, 1996). Estrous female and male rats were mated overnight, the male was removed the following day, and that day was designated day 1 of gestation. Beginning at 14 days of gestation, females were subjected to either repeated restraint stress or left undisturbed until the end of pregnancy. Restraint stress treatment consisted of confining the pregnant dam to a plastic transparent cylinder $(6 \mathrm{~cm}$ diameter $\times 20 \mathrm{~cm}$ length $)$ for $30 \mathrm{~min}$, three times daily, for the final 7 days of gestation; this procedure has been used extensively in the study of the behavioral alterations induced by PNS (eg Deminiere et al, 1992; Henry et al, 1995). Following birth, control and PNS offspring were left with their maternal dams until weaning at 21 days of age, at which time male littermates were cohoused until 10-12 weeks of age. A total of 90 males (control, $n=44$; PNS $n=46$ ) from 16 litters (control, $n=7$; PNS, $n=9$ ) were examined for cocaine selfadministration and reinstatement of cocaine-seeking behavior. Separate groups of control and PNS rats were used to examine (1) the psychomotor stimulant and neurochemical effects of acute cocaine and (2) cocaine self-administration and subsequent reinstatement of cocaine-seeking and responsiveness to cocaine. A summary of the sequence of behavioral tests is provided in Figure 1.

\section{Locomotor Activity}

Motor activity was monitored in Plexiglas activity chambers $(22 \times 43 \times 33 \mathrm{~cm})$ under dim light by a series of 16 photobeams (eight on each horizontal axis) that were interfaced to a Digiscan monitor (Omnitech Electronics, Columbus, $\mathrm{OH}$ ) and recorded by a personal computer. All male offspring from each litter (control, $n=44$ comprised three to eight rats from seven litters; PNS, $n=46$ comprised three to eight rats from nine litters) were first tested for locomotor activity in response to novelty for $60 \mathrm{~min}$. In a separate test, rats were allowed to habituate to the test chamber (60 $\mathrm{min})$, then injected intraperitoneally (i.p.) with saline $(1 \mathrm{ml} / \mathrm{mg})$ and monitored for $120 \mathrm{~min}$, and finally injected with cocaine $(7.5 \mathrm{mg} / \mathrm{kg}$, i.p.) and monitored for $120 \mathrm{~min}$. For rats not undergoing self-administration (control, $n=12$ comprised one to two rats from seven litters; PNS, $n=12$ comprised one to two rats from seven litters), the locomotor response to cocaine was conducted 3-7 days following the test for the locomotor response to

Test Condition 1:

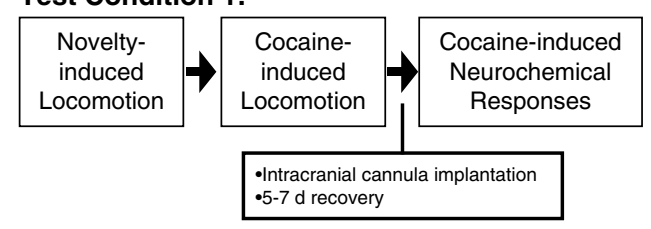

Test Condition 2:

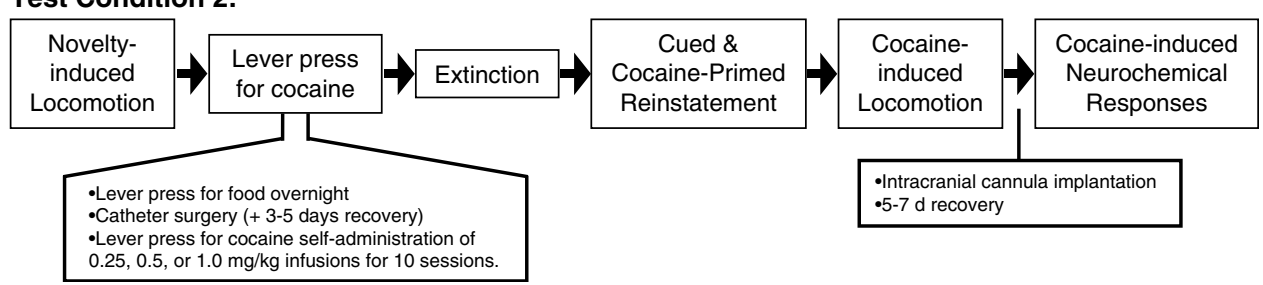

Figure I Schematic diagram illustrating sequence of behavioral tests employed in the investigation of responsiveness to cocaine in naïve rats (test condition I) and those with a history of cocaine self-administration (test condition 2). Behavioral tests were conducted on PNS (produced by maternal restraint three times per day for the last 7 days of gestation) or control rats in adulthood. 
novelty. For rats that underwent self-administration and reinstatement testing, the locomotor response to cocaine was conducted 3-7 days following the final reinstatement test (see below).

\section{Lever-Response Training}

The control ( $n=32$ comprised three to six rats from seven litters) and PNS ( $n=34$ comprised three to six rats from nine litters) rats in the cocaine self-administration and reinstatement experiment were first trained to lever press on a FR1 schedule of food reinforcement ( $45 \mathrm{mg}$ pellets; Noyes, Lancaster, $\mathrm{NH}$ ) in sound-attenuated operant conditioning chambers $(30 \times 20 \times 24 \mathrm{~cm}$ high; Med Associates Inc., St Albans, VT) during a 16-h overnight training session. The chambers were equipped with two retractable levers, a stimulus light above each lever, a food pellet dispenser between the levers, a house light on the wall opposite to the levers, and a speaker connected to a tone generator (ANL-926, Med Associates). During the session, each lever press on the active lever resulted in delivery of one food pellet only. Lever presses on the inactive lever had no programmed consequences. Rats that failed to exhibit the criterion of a minimum of 200 responses on the active lever during this session received an additional 16-h leverresponse training session.

\section{Catheter Surgery}

Rats were anesthetized using a mixture of ketamine hydrochloride and xylazine $(66$ and $1.33 \mathrm{mg} / \mathrm{kg}$, respectively, i.p.) followed by equithesin $(0.5 \mathrm{ml} / \mathrm{kg}$ of a solution of 9.72 pentobarbital sodium, 42.5 chloral hydrate, and $21.3 \mathrm{mg} / \mathrm{ml}$ magnesium sulfate heptahydrate in $44 \%$ propylene glycol, $10 \%$ ethanol solution; i.p.) and chronic indwelling catheters were implanted in the right jugular vein as described previously (Kippin et al, 2005). Catheter patency was extended by daily administration of cefazolin (10.0 mg/ml; Schein Pharmaceutical, Florham Park, NJ) in heparinized saline $(70 \mathrm{U} / \mathrm{ml}$; Elkins-Sinn, Cherry Hill, NJ) and $0.1 \mathrm{ml}$ of heparinized saline. Catheter patency was verified periodically by infusing $0.12 \mathrm{ml}$ of methohexital sodium (10 mg/ml, i.v.; Eli Lilly and Co., Indianapolis, IN).

\section{Cocaine Self-Administration}

Rats self-administered cocaine during daily 2-h sessions along a FR1 schedule of cocaine reinforcement (cocaine hydrochloride; a generous gift from the National Institute on Drug Abuse). At the start of each session, the rat's catheter was connected to a motorized pump via a liquid swivel as described previously (Kippin et al, 2005) with the house light illuminated. Active lever presses resulted in a 2-s activation of the infusion pump and a 5-s presentation of a stimulus complex, consisting of activation of the white stimulus light above the active lever and the tone generator $(78 \mathrm{~dB}, 2 \mathrm{kHz})$. Cocaine hydrochloride was dissolved in saline and delivered in a $50-\mu$ l infusion. Separate groups of rats were trained to self-administer cocaine doses of 0.25 (control, $n=10$ comprised one to two rats from seven litters; PNS, $n=12$ comprised one to two rats from eight litters), 0.5 (control, $n=11$ comprised one to two rats from seven litters; PNS, $n=12$ comprised one to two rats from nine litters), and $1.0 \mathrm{mg} / \mathrm{kg} /$ infusion (control, $n=10 \mathrm{com}$ prised one to two rats from seven litters; PNS, $n=10$ comprised one to two rats from nine litters). After each infusion, responses on the active lever had no consequences during a 20-s time-out period. Responses on the inactive lever were recorded, but had no programmed consequences. Sessions continued until each rat had obtained the selfadministration criterion of 10 sessions with at least $5 \mathrm{mg} / \mathrm{kg}$ intake per session.

\section{Extinction}

Following self-administration, all rats underwent a minimum of 7 daily 2 -h extinction sessions. During each session, responses were recorded on both levers, but had no programmed consequences (ie neither cocaine infusions nor conditioned stimuli were presented). Extinction training continued until each rat reached the extinction criterion $(\leqslant 25$ active lever responses/session on the last two consecutive days).

\section{Reinstatement of Cocaine-Seeking}

Next, each rat received five daily conditioned-cued reinstatement tests ( $2 \mathrm{~h}$ per test) during which responses on the previously active lever resulted in 5-s presentations of the light-tone-conditioned stimulus complex (but no cocaine reinforcement) followed by a 20 -s time-out period. No extinction training was employed between the conditioned-cued reinstatement tests.

Following completion of the conditioned-cued reinstatement tests, each rat received three cocaine-primed reinstatement tests. Before each reinstatement test, rats received an i.p. injection of saline vehicle, 5.0 or $10.0 \mathrm{mg}$ / $\mathrm{kg}$ cocaine immediately before being placed into the chamber for a 2-h test session. The order of dose was counterbalanced for all groups and training dose conditions. During each reinstatement test session, responses were recorded on both levers, but had no programmed consequences. Before each reinstatement test, each rat was required to reobtain the extinction criterion. The lighttone-conditioned stimulus complex was not presented during the cocaine-primed reinstatement tests.

\section{Microdialysis and HPLC}

The neurochemical responses to noncontingent cocaine exposure (15 mg/kg i.p.) were examined in PNS and control rats with or without a history of cocaine self-administration. Three to 5 days following the test for locomotor responses to noncontingent cocaine, rats were implanted with a permanent cannula directed at the NAC $(\mathrm{AP}+1.2 \mathrm{~mm}$, $\mathrm{ML} \pm 2.5 \mathrm{~mm}, \mathrm{DV}-4.8 \mathrm{~mm}$ from Bregma on a $6^{\circ}$ angle) and contralateral PFC (AP $+2.7 \mathrm{~mm}, \mathrm{ML} \pm 1.1 \mathrm{~mm}$, DV $-2.0 \mathrm{~mm}$ from Bregma on a $6^{\circ}$ angle); the left and right side target for cannulation was counterbalanced for rats in each condition. Four small screws and cranioplastic cement secured the guide cannulae to the skull. Stylets (plastics one) were placed into each cannula to prevent occlusion. The present experiment employed microdialysis procedures similar to those used previously (Szumlinski et al, 2006). 
Neurochemical responses to a cocaine injection $(15 \mathrm{mg} / \mathrm{kg}$ i.p.) were determined in the PFC and NAC on separate tests, with the order of tests counterbalanced across rats in all conditions. Five to 7 days following the cannula implantation, a microdialysis probe was inserted unilaterally into either the NAC or PFC and perfused with microdialysis buffer. Three hours later when baseline neurotransmitter levels were stable (see below), dialysate was collected in 20min fractions into $10 \mu \mathrm{l}$ of preservative for $1 \mathrm{~h}$. Samples continued to be collected for $3 \mathrm{~h}$ following a $15-\mathrm{mg} / \mathrm{kg}$ cocaine i.p. injection. One week later, each rat underwent a second microdialysis session employing identical protocol, with the exception that a microdialysis probe was placed in the contralateral cannula. For rats without a history of cocaine self-administration: control, $n=8$ comprised one to two rats from five litters, PNS, $n=8$ comprised one to two rats from six litters. For rats with a history of cocaine selfadministration: control, $n=12$ comprised two to three rats from five litters, with four trained to lever press for each cocaine dose $(0.25,0.5$, and $1.0 \mathrm{mg} / \mathrm{kg} /$ infusion $)$; PNS, $n=12$ comprised two to three rats from six litters, with four trained to lever press for each cocaine dose. Analyses of samples from some rats could not be completed due to technical problems (probe failure, cannula obstruction, or headcap displacement). This attrition is reflected in statistical degrees of freedom and is reported in group size (see below).

As described previously (Lominac et al, 2006; Szumlinski et al, 2007), the high-performance liquid chromatography (HPLC) system consisted of a Coularray detector, a Model 542 autosampler, and two Model 582 solvent-delivery systems (ESA Inc., Bedford, MA), which enabled the sequential detection of monoamines and amino acids from each dialysate sample. Dopamine and serotonin were separated using a MD-150 $\times 3.2$ column and detected using an ESA 5014B analytical cell with two electrodes (E1, $-150 \mathrm{mV} ; \mathrm{E} 2,+220 \mathrm{mV})$. Glutamate was separated using a CAPCELL PAK C18 MG column $(5 \mathrm{~cm}$; Shiseido Company Ltd., Tokyo, Japan) and detected using an ESA 5011A analytical cell with two electrodes (E1, $+150 \mathrm{mV}$; E2, $+550 \mathrm{mV}$ ), following precolumn derivatization with $o$-phthalaldehyde using the autosampler. Neurotransmitter content in each sample was analyzed by peak height and was compared with external standard curves (one for monoamines and one for glutamate) for quantification using ESA Coularray for Windows software.

\section{Histology}

Rats were killed, their brains removed and sliced into $30-\mu \mathrm{m}$ coronal sections, and probe placements were verified under a light microscope. Only rats whose microdialysis probes were located within the boundaries of the NAC or PFC according to the atlas of Paxinos and Watson (Paxinos and Watson, 1986) were included in the statistical analysis.

\section{Data Analysis}

Mixed factors analyses of variance (ANOVA) were used to analyze locomotor activity, responses on the active lever and inactive levers, cocaine intake, and neurotransmitter levels, with group (control or PNS), training dose, and session as factors, where appropriate. Interaction effects were further investigated using simple main effects tests (one-way ANOVA or $t$-test) and/or Tukey post hoc tests, where appropriate.

\section{RESULTS}

\section{Locomotor Activity Response to Novelty}

PNS rats display enhanced locomotor responses to novel environments relative to controls (Deminiere et al, 1992; Vallee et al, 1997). Consistent with these previous reports, PNS rats exhibited higher locomotor activity during initial exposure to a novel environment than did control rats (Figure 2a; $\mathrm{t}_{85}=2.74, p<0.05$ ). No significant group effects were found on measures of vertical activity or stereotypy (data not shown).

\section{Locomotor Activity Response to Noncontingent Cocaine in Rats without a History of Self-Administration}

PNS rats exhibit heightened amphetamine-induced locomotion and locomotor sensitization (Deminiere et al, 1992; Henry et al, 1995). Similar to these earlier amphetamine studies, cocaine-naïve PNS rats exhibited more locomotor activity than controls in response to an acute cocaine injection (Figure $2 \mathrm{~b}$ ). There was a significant interaction between group and time $\left(\mathrm{F}_{3,66}=3.93, p<0.05\right)$, with higher horizontal activity in the PNS rats relative to the control rats at 1 and $2 \mathrm{~h}$ following cocaine injection, but no significant differences between groups following saline injection. Both groups of rats showed increased vertical activity and stereotypy counts following the cocaine injection, but there were neither significant effects of group nor interactions between group and time (data not shown).
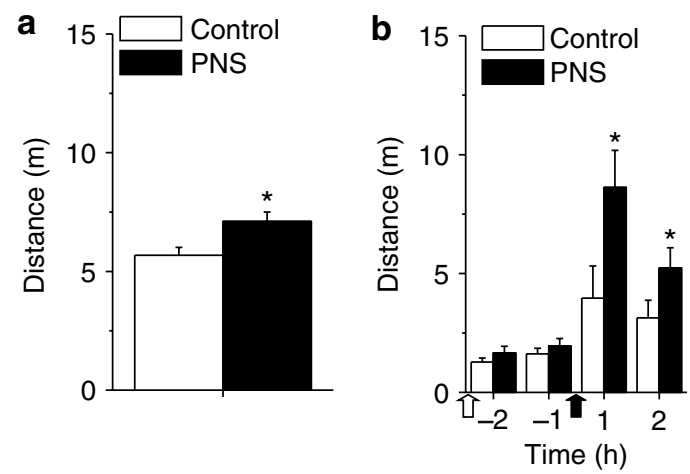

Figure 2 Novelty- and cocaine-induced locomotor activity exhibited by PNS and control rats in distance $(\mathrm{m})$ as measured by photobeam breaks (a) Response to initial placement in a novel test environment in a 60-min test in control ( $n=44$ comprised three to eight rats from seven litters) and PNS ( $n=46$ comprised three to eight rats from nine litters) rats. (b) Response to vehicle injection (empty arrow) and cocaine injection (I $5 \mathrm{mg} /$ kg i.p., filled arrow) in sequential 120 min tests in control $(n=12$ comprised one to two rats from seven litters) and PNS rats ( $n=12$ comprised one to two rats from seven litters) without a history of cocaine-experience. Data shown as mean \pm SEM; symbol indicates a significant difference between the PNS and control rats $(* p<0.05)$. 


\section{Neurochemical Response to Noncontingent Cocaine in Rats without a History of Self-Administration}

Next, in vivo microdialysis and HPLC were employed to determine the influence of PNS on corticoaccumbens basal and cocaine-stimulated changes in neurotransmission. PNS rats showed alterations in NAC dopamine, serotonin, and glutamate neurotransmission relative to controls. Figure 3 summarizes (a) the probe placements in the NAC, $(b-d)$ absolute value, and $\left(b^{\prime}-d^{\prime}\right)$ changes from baseline in extracellular levels of dopamine, serotonin, and glutamate before and after a challenge injection of $15 \mathrm{mg} / \mathrm{kg}$ cocaine. Relative to controls, PNS rats displayed higher NAC dopamine levels in all samples (Figure $3 b$; interaction between group and time, $\left.\mathrm{F}_{11,121}=2.94, p<0.05\right)$ and a greater dopamine change from baseline following the cocaine challenge (Figure $3 \mathrm{~b}^{\prime}$; interaction between group and time, $\left.\mathrm{F}_{11,121}=1.98, p<0.05\right)$. Conversely, PNS rats exhibited reduced serotonin in all samples relative to control (Figure 3c; effect of group, $\mathrm{F}_{1,11}=4.20, p<0.05$ ) but both groups exhibited an equivalent change from baseline following cocaine challenge (Figure $3 c^{\prime}$; effect of time, $\left.\mathrm{F}_{11,121}=2.63, p<0.05\right)$. PNS exhibited reduced NAC glutamate levels before, but not after, the cocaine injection compared with controls (Figure 3d; interaction between group and time, $\left.\mathrm{F}_{11,121}=2.06, p<0.05\right)$ and the PNS rats, but not the controls, exhibited a cocaine-induced elevation from baseline NAC glutamate (Figure $3 \mathrm{~d}^{\prime}$; interaction between group and time, $\left.\mathrm{F}_{11,121}=1.94, p<0.05\right)$.

In contrast to the NAC, we did not detect any significant differences between PNS and control rats in PFC neurotransmitter levels in rats without a history of cocaine selfadministration. Figure 4 summarizes (a) the probe placements in the PFC, (b-d) absolute value, $\left(b^{\prime}-d^{\prime}\right)$ and changes from baseline in extracellular levels of dopamine, serotonin, and glutamate before and after a challenge injection of $15 \mathrm{mg} / \mathrm{kg}$ cocaine. Both PNS and control rats exhibited a rise in PFC dopamine levels following the cocaine challenge that was biphasic with respect to time. (Figure $4 \mathrm{~b}$ and $\mathrm{b}^{\prime}$; effect of time on absolute values, $\mathrm{F}_{11,99}=3.47, p<0.01$ and effect of time on change from baseline, $\mathrm{F}_{11,99}=3.05, p<0.01$ ), but no significant effect of group or interaction between group a

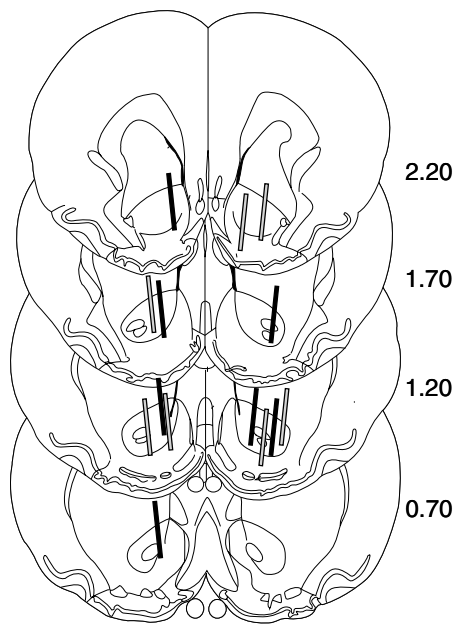

b

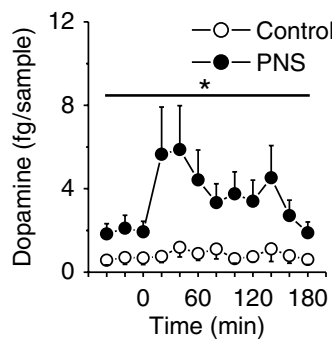

C

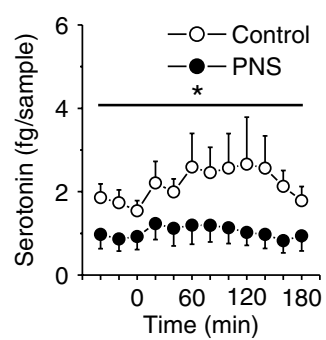

d

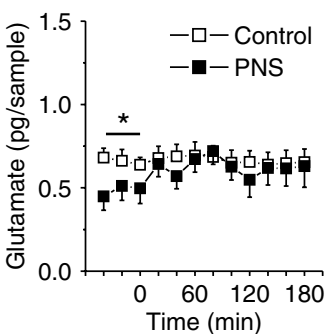

b'

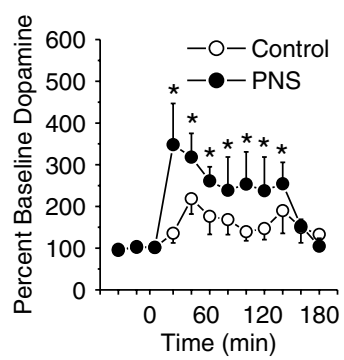

$\mathbf{c}^{\prime}$

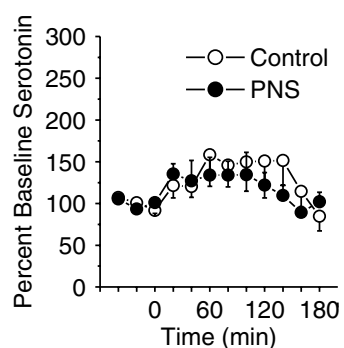

d'

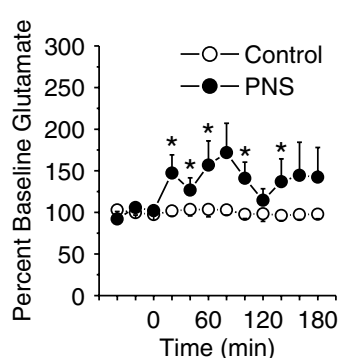

Figure 3 Basal and cocaine-stimulated ( $15 \mathrm{mg} / \mathrm{kg}$, i.p.) neurotransmitter levels in the NAC in PNS ( $n=7$ comprised one to two rats from five litters) and control ( $n=7$ comprised one to two rats from five litters) rats without a history of cocaine self-administration. (a) Summary of the NAC placements of the active membrane of the microdialysis probes of PNS (solid lines) and control (gray-filled lines) rats. (b-d) Absolute levels of dopamine, serotonin, and glutamate in the NAC before and after a cocaine challenge. ( $b^{\prime}$ and $d^{\prime}$ ) Changes from baseline in NAC dopamine, serotonin, and glutamate levels following a cocaine challenge; data shown as mean \pm SEM transformed to percent change from the basal levels derived from the average of the final three prechallenge samples. Symbol indicates a significant difference between the PNS and control rats $(* p<0.05)$. 
a

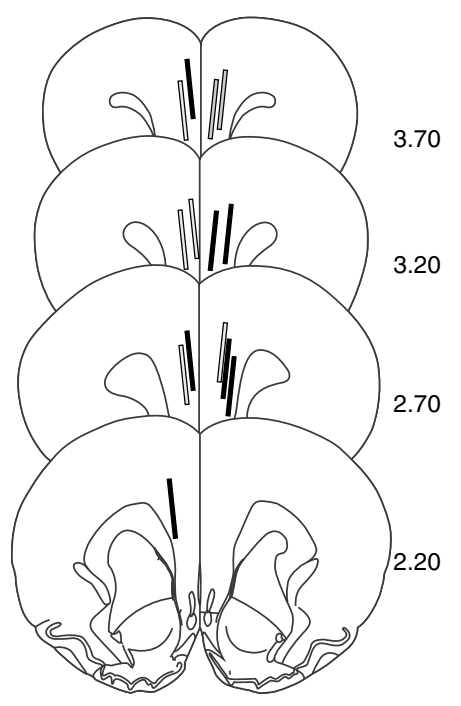

b

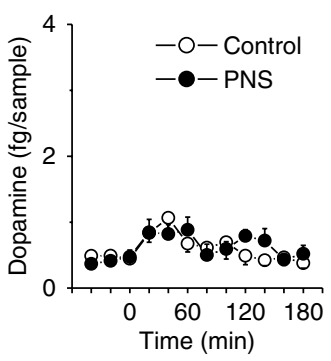

C

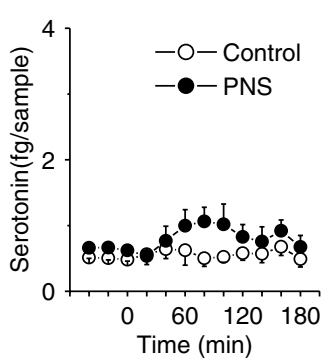

d

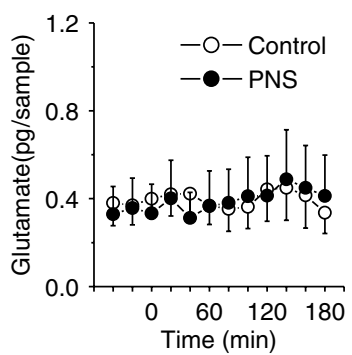

b'

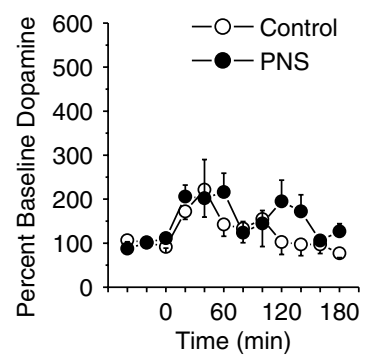

$c^{\prime}$

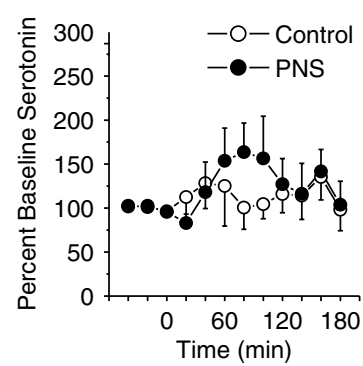

d'

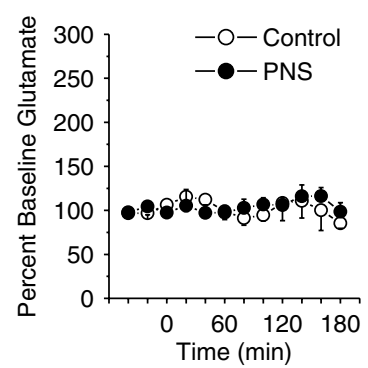

Figure 4 Basal and cocaine-stimulated ( $15 \mathrm{mg} / \mathrm{kg}$, i.p.) neurotransmitter levels in the PFC in PNS (for dopamine and serotonin, $n=6$ comprised one to two rats from four litters; for glutamate, $n=7$ comprised one to two rats from five litters) and control (for dopamine and serotonin, $n=5$ comprised one to two rats from four litters; for glutamate, $n=4$ comprised one rat from four litters) rats without a history of cocaine self-administration. (a) Summary of the PFC placements of the active membrane of the microdialysis probes of PNS (solid lines) and control (gray-filled lines) rats. (b-d) Absolute levels of dopamine, serotonin, and glutamate in the PFC before and after a cocaine challenge. ( $b^{\prime}$ and $d^{\prime}$ ) Changes from baseline in PFC dopamine, serotonin, and glutamate levels following a cocaine challenge; data shown as mean \pm SEM transformed to percent change from the basal levels derived from the average of the final three prechallenge samples.

and time $(p>0.05)$. For PFC serotonin and glutamate (Figure $4 c, c^{\prime}, d$, and $d^{\prime}$ ), there were no significant effects of group or time or interaction between group and time (all $p>0.05)$ although there was a trend towards a cocaineinduced increase in serotonin in PNS rats.

\section{Cocaine Self-Administration}

Almost all rats completed acquisition of lever pressing for food reinforcement during a single session (one of 32 control and two of $34 \mathrm{PNS}$ rats required a second session to obtain the criterion of 200 active lever presses) and there were no differences between PNS and control rats in learning to exhibit active lever responses for food pellets (control, $521 \pm 32.2$; PNS, $483 \pm 31.4 ; p>0.05$ ) and exhibit equivalent inactive lever responses (control, 54.6 \pm 6.2 ; PNS, $49.0 \pm 8.90 ; p>0.05)$.

Following implantation of the jugular catheter, control and PNS rats were trained to self-administer i.v. cocaine at doses of $0.25,0.5$, and $1.0 \mathrm{mg} / \mathrm{kg} /$ infusion $(n=10-12$ rats per group per dose). All rats achieved the self-administration criterion of 10 sessions with cocaine intake of at least $5 \mathrm{mg} / \mathrm{kg}$. Rats trained at the $0.25 \mathrm{mg} / \mathrm{kg}$ infusion dose took slightly more sessions to achieve the self-administration criterion $(13.13 \pm 0.71$ sessions $)$ than did the 0.5 $(11.20 \pm 0.37)$ or $1.0(10.68 \pm 0.25) \mathrm{mg} / \mathrm{kg} /$ infusion doses (one-way ANOVA; $\mathrm{F}_{2,61}=7.01, p<0.05$ ), but there was no group effect or interaction between group and dose on the time taken to reach the criterion. Despite a trend towards an increase in cocaine intake in the PNS rats trained at the highest cocaine dose, there were no significant effects or interaction between group and training dose during the last three sessions (Figure 5a; $p>0.05$ ). However, both control and PNS rats in the lowest training dose condition displayed more active lever responses during the last three sessions than did rats trained with the other two doses (Figure $5 \mathrm{~b}$ ) as supported by a significant main effect of dose $\left(\mathrm{F}_{2,58}=8.46\right.$, $p<0.05)$, with rats trained at the $0.25 \mathrm{mg} / \mathrm{kg} /$ infusion dose responding more than rats at the other two doses $(p<0.05)$. There were no significant effects of group or interactions 

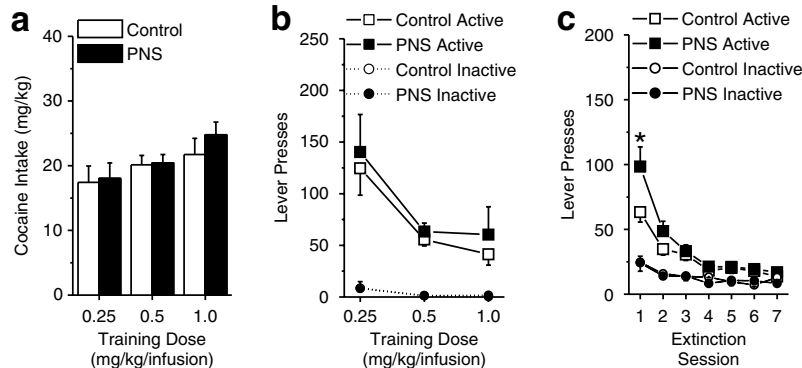

Figure 5 Cocaine self-administration and extinction behavior exhibited in PNS and control rats. During self-administration, active lever responses resulted in the delivery of a cocaine infusion and simultaneous presentation of a light \pm tone stimulus complex. Each reinforced lever press was followed by a 20 -s time-out period. During extinction, active lever responses had no programmed consequences. Separate groups of rats were trained to selfadminister cocaine doses of $0.25 \mathrm{mg} / \mathrm{kg} /$ infusion (control, $n=10$ comprised one to two rats from seven litters; PNS, $n=12$ comprised one to two rats from eight litters), $0.5 \mathrm{mg} / \mathrm{kg} /$ infusion (control, $n=1$ I comprised one to two rats from seven litters; PNS, $n=12$ comprised one to two rats from nine litters), and $1.0 \mathrm{mg} / \mathrm{kg} /$ infusion (control, $n=10$ comprised one to two rats from seven litters; PNS, $n=10$ comprised one to two rats from nine litters). (a) Intake $(\mathrm{mg} / \mathrm{kg})$ per daily session averaged across the last three sessions for PNS and control rats trained with $0.25,0.5$, and $1.0 \mathrm{mg} / \mathrm{kg}$ infusions. (b) Active and inactive lever responses per daily session averaged across the last three sessions for PNS and control rats trained with 0.25 , 0.5 , and $1.0 \mathrm{mg} / \mathrm{kg}$ infusions. (c) Active and inactive lever responses during daily extinction sessions for PNS and control rats (data collapsed across training infusion doses; one PNS rats trained with $1.0 \mathrm{mg} / \mathrm{kg} /$ infusion failed to exhibit extinction of active lever pressing and was omitted from analyses). Data shown as mean $\pm \mathrm{SEM}$; symbol indicates a significant difference between the PNS and control rats $(* p<0.05)$.

between group and training dose $(p>0.05)$, nor were there significant effects or interactions of group or training dose on the number of inactive lever responses.

\section{Extinction of Lever Responding}

PNS rats exhibited greater initial responding during extinction than did control rats and this effect was independent of the cocaine-training dose during selfadministration (Figure $5 \mathrm{c}$ ). There was a significant interaction between group and session $\left(\mathrm{F}_{6,342}=2.55, p<0.05\right)$ with PNS rats displaying more active lever responses during the first session $(p<0.05)$, but no group differences were found on other sessions, nor were there any significant effects or interactions between the cocaine-training doses $(p>0.05)$. In contrast, both PNS and control rats showed equivalent elevations in responding to the inactive lever during the first extinction session relative to all other sessions $\left(\mathrm{F}_{6,342}=11.91, p<0.05\right)$, but responding did not differ between any other session; nor were there any significant effects or interactions between group and the cocainetraining doses. Furthermore, the PNS rats took slightly more sessions to obtain the extinction criterion than did controls $\left(\mathrm{F}_{1,57}=4.70, p<0.05\right)$; again, this effect was independent of training dose (mean \pm SEM for control and PNS rats were $7.07 \pm 0.05$ and $7.75 \pm 0.25$, respectively). One PNS rat trained at the $1.0 \mathrm{mg} / \mathrm{kg} /$ infusion dose failed to reach the extinction criterion within 25 sessions and the data from this rat was excluded from the sessions to extinction criterion and reinstatement analyses.
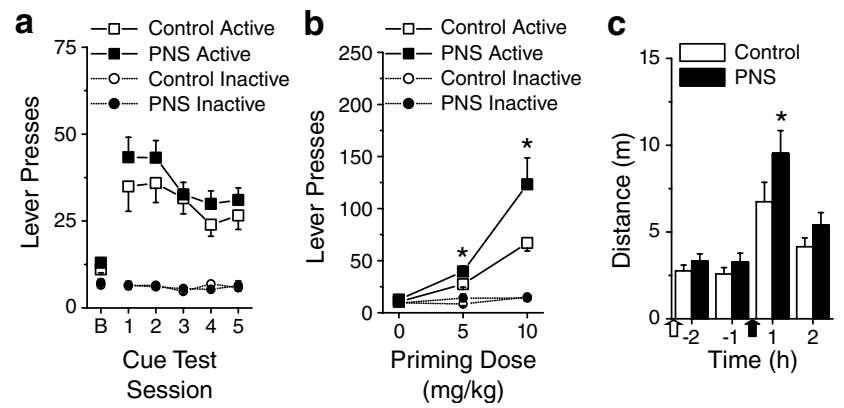

Figure 6 Conditioned-cued reinstatement of cocaine-seeking, cocaineprimed reinstatement of cocaine-seeking and post-self-administration cocaine-induced locomotor activity exhibited by PNS and control rats. Rats were trained to self-administer cocaine doses of $0.25 \mathrm{mg} / \mathrm{kg} /$ infusion (control, $n=10$ comprised one to two rats from seven litters; PNS, $n=12$ comprised one to two rats from eight litters), $0.5 \mathrm{mg} / \mathrm{kg} /$ infusion (control, $n=11$ comprised one to two rats from seven litters; PNS, $n=12$ comprised one to two rats from nine litters), and $1.0 \mathrm{mg} / \mathrm{kg} /$ infusion (control, $n=10$ comprised one to two rats from seven litters; PNS, $n=10$ comprised one to two rats from nine litters) but the lack of training dose effects or interactions warranted collapsing data across this variable for presentation. (a) Responses on the active and inactive lever during the last two extinction session served as a baseline (b) for the subsequent five daily conditioned cued reinstatement tests in which active lever responses resulted in presentation of the light \pm tone stimulus complex (FRI with 20-s time-out period). (b) Responses on the active and inactive lever during primed reinstatement tests after i.p. injection with 0 (vehicle), 5 , or $10 \mathrm{mg} /$ $\mathrm{kg}$ cocaine under extinction conditions. (c) Locomotor activity following vehicle injection (empty arrow) and cocaine injection ( $15 \mathrm{mg} / \mathrm{kg}$ i.p., filled arrow). Data shown as mean $\pm \mathrm{SEM}$; symbol indicates a significant difference between the PNS and control rats $(* p<0.05)$.

\section{Conditioned-Cued Reinstatement of Cocaine-Seeking}

Contingent re-exposure to the cocaine-paired cues following self-administration produced an increase in active lever responses in both control and PNS rats, but there were no significant effects of group or training dose (Figure 6a). There was a significant effect of session $\left(\mathrm{F}_{5,285}=18.87\right.$, $p<0.05)$ with increased responding on cue tests $1-5$ relative to the extinction baseline and higher responding on cue tests 1 and 2 relative to cue tests 4 and $5(p<0.05)$. However, there were no other significant between-sessions differences nor were there any significant effects of group, training dose, or interaction between group and training dose. There were no significant group, training dose, session, or interaction effects for inactive lever responding.

\section{Cocaine-Primed Reinstatement of Cocaine-Seeking}

Exposure to noncontingent cocaine ( 5 and $10 \mathrm{mg} / \mathrm{kg}$, i.p.) produced greater reinstatement of cocaine-seeking in PNS rats than control rats, independent of the cocaine-training doses (Figure 6b). There was a significant interaction between group and session $\left(\mathrm{F}_{2,114}=5.21, p<0.05\right)$, with PNS rats exhibiting a modest increase in responding following the $5 \mathrm{mg} / \mathrm{kg}$ challenge and a substantial increase in responding following the $10 \mathrm{mg} / \mathrm{kg}$ test challenge relative to controls $(p<0.05)$; there were no significant effects or interaction between training doses. No significant effects or interaction were detected for responding on the inactive lever. 


\section{Locomotor Response to Noncontingent Cocaine Following Self-Administration}

In response to an injection of cocaine ( $15 \mathrm{mg} / \mathrm{kg}$, i.p.), cocaine-experienced PNS rats exhibited increased locomotor activity relative to controls (Figure $6 \mathrm{c}$ ). There was a significant interaction between group and time $\left(\mathrm{F}_{3,189}=4.87, p<0.05\right)$, with higher activity in the first hour following cocaine injection than all other times, in the second hour following cocaine injection relative to the $2 \mathrm{~h}$ preceding the cocaine injection, and in the PNS rats relative to the control rats during the first hour following cocaine injection $(p<0.05)$. Both groups of rats showed increased vertical activity and stereotypy counts following cocaine injection, but there were neither significant effects of group nor interactions between group and time $(p<0.05$, data not shown).

\section{Neurochemical Response to Noncontingent Cocaine Following Cocaine Self-Administration}

To relate observed differences in behavioral responding to changes in NAC and PFC neurochemistry, a subset of the control and PNS rats that completed self-administration (with equal numbers from each training dose and there were no significant effects of training dose on any aspect of neurochemistry, $p>0.05)$ and reinstatement testing were examined in microdialysis sessions in an identical manner as for rats without a history of cocaine self-administration (see above). Figure 7 summarizes (a) the probe placements in the NAC, $(b-d)$ absolute value, $\left(b^{\prime}-d^{\prime}\right)$ and changes from baseline in extracellular levels of dopamine, serotonin, and glutamate before and after a challenge injection of $15 \mathrm{mg} / \mathrm{kg}$ cocaine. PNS rats and controls with a history of cocaine selfadministration exhibited equivalent levels of NAC dopamine and both groups showed a cocaine-induced elevation in NAC dopamine; however, the magnitude and duration of the cocaine-induced elevation was greater in PNS rats than controls (Figure $7 \mathrm{~b}$ and $\mathrm{b}^{\prime}$; interaction between group and time on absolute values, $\mathrm{F}_{11,198}=1.94, p<0.05$ and interaction between group and time on change from baseline, $\left.\mathrm{F}_{11,198}=2.17, p<0.01\right)$. For NAC serotonin, both groups showed equivalent basal levels and cocaine-induced elevations during the first 80 post-injection (Figure $7 c$ and $c^{\prime}$; effect of time on absolute values, $\mathrm{F}_{11,209}=2.45, p<0.01$ and effect of time on change from baseline, $F_{11,209}=3.59$, $p<0.01)$. Further, PNS rats displayed lower absolute values of NAC glutamate prior to and following the cocaine challenge and NAC glutamate increased in both groups following the cocaine challenge (Figure $7 \mathrm{~d}$; effect of group $\left.F_{1,20}=4.68, p<0.05\right)$, effect of time $\left.F_{11,220}=4.40, p<0.05\right)$, moreover, the magnitude of the cocaine-induced elevation
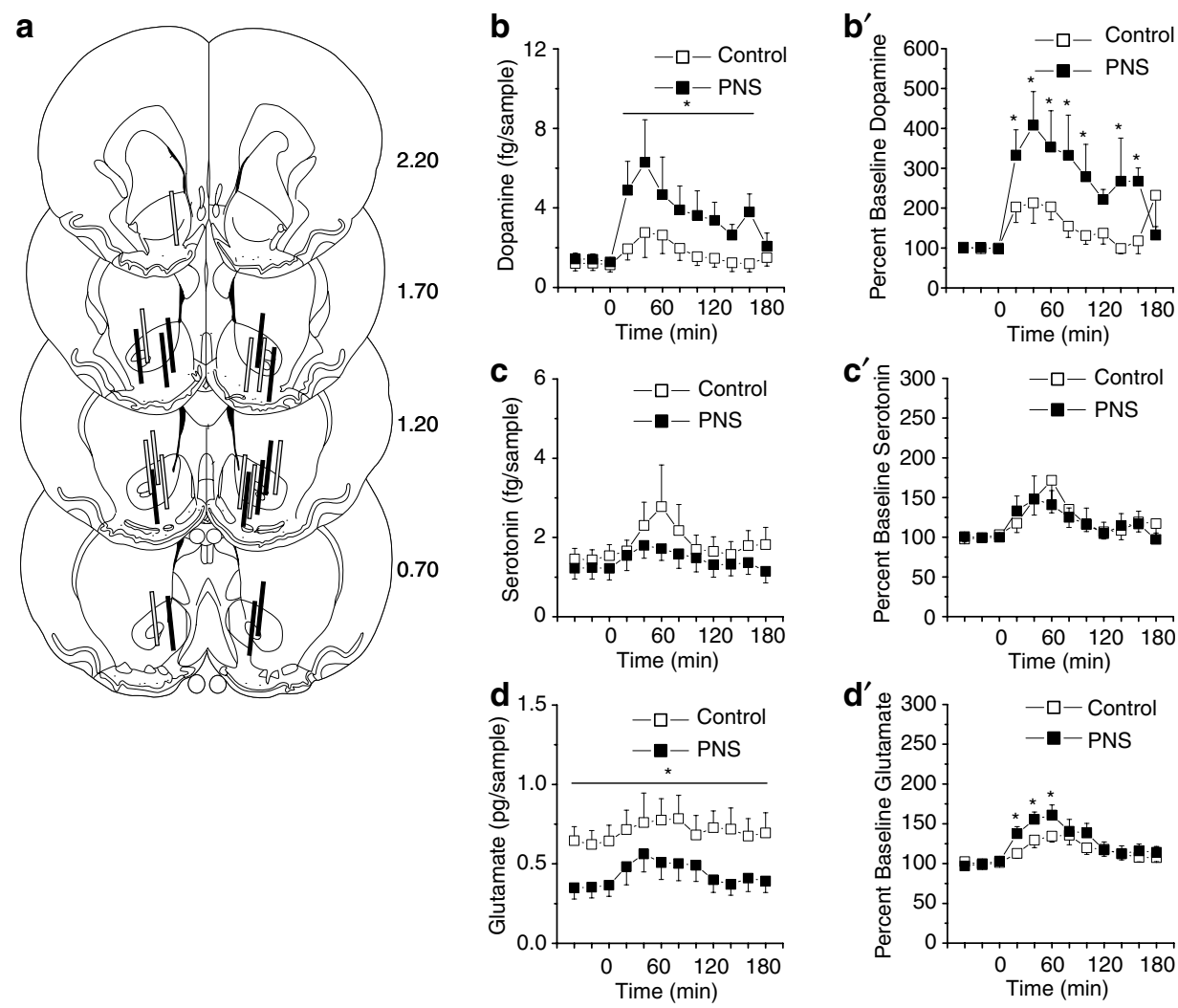

Figure 7 Basal and cocaine-stimulated ( $15 \mathrm{mg} / \mathrm{kg}$, i.p.) neurotransmitter levels in the NAC in PNS (for dopamine and serotonin, $n=9$ comprised one to three rats from six litters; for glutamate, $n=1$ I comprised one to three rats from six litters) and control (for dopamine, serotonin, and glutamate, $n=1$ I comprised one to three rats from five litters) rats following a history of cocaine self-administration. (a) Summary of the NAC placements of the active membrane of the microdialysis probes of PNS (solid lines) and control (gray-filled lines) rats. (b-d) Absolute levels of dopamine, serotonin, and glutamate in the NAC before and after a cocaine challenge. ( $b^{\prime}$ and $d^{\prime}$ ) Changes from baseline in NAC dopamine, serotonin, and glutamate levels following a cocaine challenge; data shown as mean \pm SEM transformed to percent change from the basal levels derived from the average of the final three prechallenge samples. Symbol indicates a significant difference between the PNS and control rats $(* p<0.05)$. 
in NAC glutamate was greater in the PNS rats relative to controls (Figure $7 \mathrm{~d}^{\prime}$; interaction between group and time $\left.F_{11,209}=2.14, p<0.05\right)$.

Cocaine injection also increased PFC extracellular levels of the three neurotransmitters, but as observed for cocainenaïve subjects, there were no group differences for any of the neurotransmitters examined. Figure 8 summarizes (a) the probe placements in the PFC, (b-d) absolute value, $\left(b^{\prime}-d^{\prime}\right)$ and changes from baseline in extracellular levels of dopamine, serotonin, and glutamate before and after a challenge injection of $15 \mathrm{mg} / \mathrm{kg}$ cocaine. Relative to controls, PNS rats exhibited higher dopamine levels in most of the dialysate samples before and after the cocaine challenge (Figure 8b; interaction between group and time on absolute values, $\mathrm{F}_{11,220}=1.83, p=0.05$ ) but the cocaine challenge produced equivalent elevations above baseline levels of PFC dopamine in PNS rats and controls (Figure $8 \mathrm{~b}^{\prime}$; effect of time on change from baseline, $\mathrm{F}_{11,220}=3.16, p<0.01$; effect of group and interaction between group and time, $p>0.05$ ). The cocaine challenge produced a modest elevation of PFC serotonin above baseline (Figure $8 c$ and $c^{\prime}$; effect of time on absolute values, $\mathrm{F}_{11,198}=1.71, p=0.07$ and effect of time on change from baseline, $\left.\mathrm{F}_{11,198}=1.99, p<0.05\right)$; although this effect appears to be driven mainly by changes in the PNS rats, the effect of group and interaction between group and time failed to reach statistical significance $(p>0.05)$. Lastly, the cocaine challenge produced an equivalent latent increase in PFC glutamate in PNS rats and controls (Figure $8 \mathrm{~d}$ and $\mathrm{d}^{\prime}$; effect of time on absolute values, $\mathrm{F}_{11,198}=3.40$, $p<0.01$, effect of time on change from baseline $\left.\mathrm{F}_{11,198}=4.46, p<0.01\right)$, but no effect of group or interaction between group and time were detected $(p>0.05)$.

\section{DISCUSSION}

The current investigation provides the first analysis of the influence of PNS on adult behavioral and neurochemical responses to cocaine. Cocaine-naïve PNS rats exhibited increased locomotor activity in response to both a novel environment and noncontingent cocaine injections. Moreover, PNS rats with a history of cocaine self-administration exhibited increased cocaine-seeking (as measured by unreinforced active lever presses) during extinction training and cocaine-primed reinstatement following operant selfadministration of cocaine. Furthermore, cocaine-naïve PNS rats exhibited increased NAC dopamine and reduced NAC serotonin and glutamate with enhanced dopamine and glutamate neurotransmission in the NAC following a cocaine challenge, whereas cocaine-experienced PNS rats exhibited reduced NAC glutamate and increased PFC a

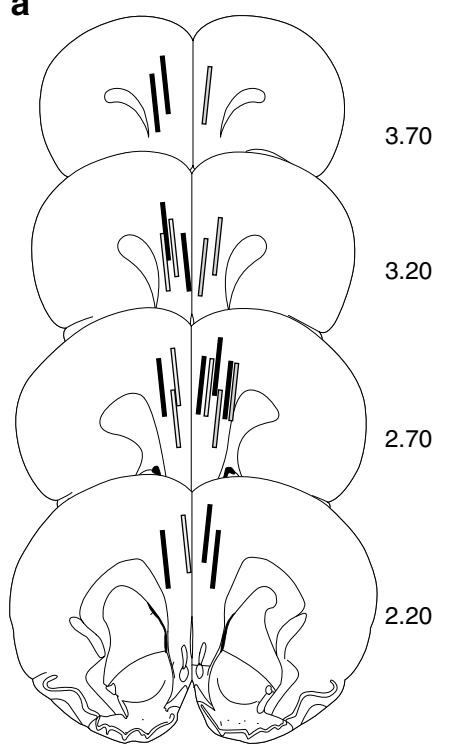

b

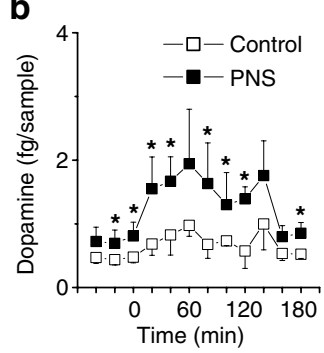

C
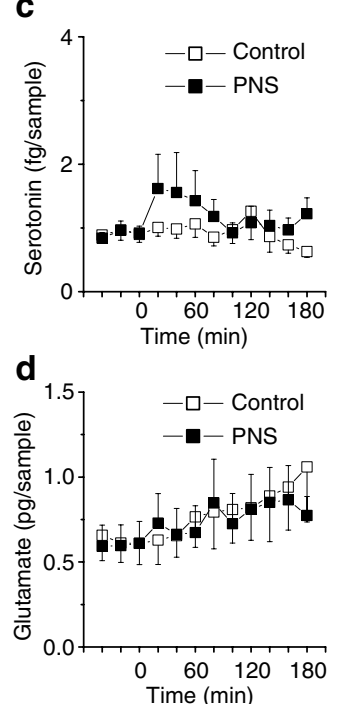

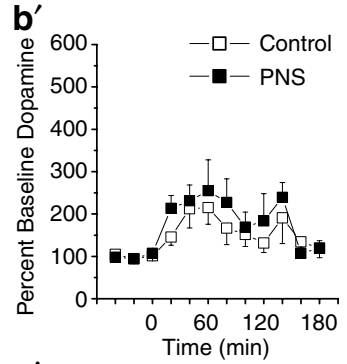

$\mathbf{c}^{\prime}$
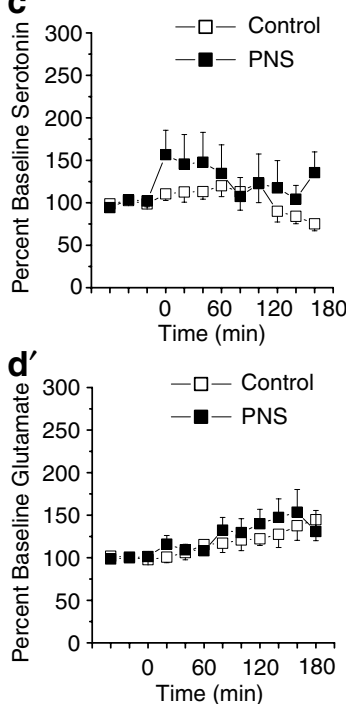

Figure 8 Basal and cocaine-stimulated ( $15 \mathrm{mg} / \mathrm{kg}$, i.p.) neurotransmitter levels in the PFC in PNS (for dopamine, $n=1 \mid$ comprised one to three rats from six litters; for serotonin and glutamate, $n=10$ comprised one to two rats from six litters) and control (for dopamine, $n=1 \mid$ comprised one to three rats from five litters; for serotonin and glutamate, $n=10$ comprised one to three rats from five litters) rats following a history of cocaine self-administration. (a) Summary of the PFC placements of the active membrane of the microdialysis probes of PNS (solid lines) and control (gray-filled lines) rats. (b-d) Absolute levels of dopamine, serotonin, and glutamate in the PFC before and after a cocaine challenge. ( $b^{\prime}$ and $\left.d^{\prime}\right)$ Changes from baseline in PFC dopamine, serotonin, and glutamate levels following a cocaine challenge; data shown as mean \pm SEM transformed to percent change from the basal levels derived from the average of the final three prechallenge samples. Symbol indicates a significant difference between the PNS and control rats $(* p<0.05)$. 
dopamine with enhanced NAC glutamate and dopamine and PFC dopamine neurotransmission following a cocaine challenge. These findings demonstrate that PNS rats have (1) an increased sensitivity to the locomotor-stimulating properties of cocaine, (2) a higher propensity for cocaineseeking, and (3) a heightened corticolimbic dopamine and glutamate response to cocaine.

\section{Influence of PNS on Behavioral Responses to Cocaine}

The primary purpose of this study was to determine whether or not PNS influences cocaine self-administration and reinstatement in the rat. PNS rats displayed substantial increases in cocaine-seeking behavior during extinction training and following priming with a moderate dose of cocaine $(10 \mathrm{mg} / \mathrm{kg})$, while a very modest increase in cocaine-seeking also occurred after the low dose of cocaine $(5 \mathrm{mg} / \mathrm{kg})$. In contrast, we did not observe alterations in cocaine self-administration in PNS rats, despite employing multiple cocaine doses encompassing a major portion of the range of doses supporting self-administration behavior. Moreover, PNS rats did not differ from controls for conditioned-cued reinstatement. Consistent with this pattern of results, we recently reported that individual histories can elevate the reinstating properties of specific environmental stimuli (ie cocaine-paired cues or noncontingent cocaine) in the absence of differences in cocaine intake (Kippin et al, 2006), demonstrating that these elements of cocaine-seeking behavior are dissociable. The only other study that examined the effect of PNS on psychostimulant drug self-administration found a marked (approximately four-fold) elevation in amphetamine intake by the fifth training session (Deminiere et al, 1992). However, the effects of PNS on reinstatement of amphetamine-seeking behavior or on responsiveness to other drugs of abuse have not been investigated. Together, the data to date suggest that PNS increases addiction vulnerability to psychostimulant drugs, which can manifest as increased intake (amphetamine) or an increased propensity to relapse to drug-seeking (cocaine).

Although this is the first report for PNS and cocaine selfadministration in adulthood, recent studies have investigated the effects of early postnatal isolation on subsequent cocaine self-administration in adulthood. In several of these studies, neonatal stress produced modest enhancements in cocaine intake in a variety of self-administration protocols (Kosten et al, 2000, 2004a, 2006; Lynch et al, 2005; Zhang et al, 2005; see however Marquardt et al, 2004; Matthews et al, 1999). In contrast to our findings, Zhang et al, (2005) reported no effect of neonatal isolation on cocaine-primed reinstatement, despite elevated cocaine intake in the same animals. However, there are a number of procedural differences in that study compared with the present one, in particular the employment of i.v. priming infusions which produced maximal responding in their controls that appears to be less than $40 \%$ of that exhibited by controls in the present study. Similar to the current results, neonatal isolation failed to alter conditioned-cued reinstatement of cocaine-seeking (Lynch et al, 2005). Further, this latter study found that neonatal isolation enhanced stressinduced reinstatement of cocaine-seeking. Based on the extensive evidence of hyper-responsiveness to stress in PNS rats, it would be of particular interest in the future to investigate stress-induced reinstatement in PNS rats. Thus, although there are increases in cocaine-seeking behavior following different models of early environmental stress (eg prenatal $v s$ early postnatal stress), it is unclear if there are real or merely apparent differences exhibited following these treatments. Taken together, these findings suggest that early environmental stress increases cocaine addiction vulnerability, with the present data demonstrating an increased propensity for relapse to drug-taking.

Adult PNS rats exhibited elevated behavioral responsiveness to both environmental stimuli and psychostimulant drugs. Our observation that drug-naïve PNS rats exhibited elevated locomotor responsiveness to a novel environment is consistent with reports from other laboratories employing PNS or prenatal corticosterone treatments (eg Deminiere et al, 1992; Diaz et al, 1995; Vallee et al, 1997). Further, we observed increased cocaine-induced locomotor activity relative to controls in PNS rats that were either cocainenaïve or had a history of cocaine self-administration, extending previous observations of enhanced amphetamine-induced locomotor activity in drug-naïve PNS or prenatal corticosterone-treated rats (Deminiere et al, 1992; Diaz et al, 1995; Koenig et al, 2005). Although increased sensitization of amphetamine-induced locomotion has been reported in another study (Henry et al, 1995), inspection of Figure $2 \mathrm{~b}$ and $6 \mathrm{c}$ suggests that the PNS rats in the present study underwent minimal sensitization of cocaine-induced locomotion following cocaine self-administration. However, it is not clear if this is due to the inability of cocaine to produce sensitization in PNS rats or due to procedural factors such as the cocaine challenge dose, time between self-administration and testing, or age differences. Nevertheless, these present findings suggest that PNS rats are presensitized to the psychomotor-activating effects of stimulant drugs.

Amphetamine-induced sensitization before cocaine selfadministration has been shown to increase cocaine selfadministration under a progressive ratio schedule of reinforcement (Suto et al, 2002, 2003) or during long-access self-administration sessions (Ferrario and Robinson, 2006). Although PNS rats in the present study appeared to be presensitized to the psychomotor stimulant effects of cocaine, we failed to observe any effect on self-administration behavior which may reflect the employment of a relatively brief (2-h) access and a continuous reinforcement schedule. Importantly, enhanced cocaine-induced psychomotor effects, by themselves, cannot fully account for increased cocaine-seeking behavior exhibited by the PNS rats because these latter increases were specific to the active lever and occurred during extinction training when no cocaine was administered.

\section{Influence of PNS on Neurochemical Responses to Cocaine}

The present study also provides the first examination of the influence of PNS on stimulant-induced changes in extracellular neurotransmitter levels within the corticoaccumbens pathway and revealed a complex pattern of alterations in basal and cocaine-stimulated levels of dopamine, serotonin, and glutamate (summarized in Table 1) - it 
Table I Summary of PNS-Induced Basal and Cocaine-Stimulated Changes in the NAC and PFC of Cocaine-Naive and -Experienced Rats

\begin{tabular}{|c|c|c|c|c|}
\hline & \multicolumn{2}{|c|}{ Naïve } & \multicolumn{2}{|c|}{ Cocaine-experienced } \\
\hline & Basal & $\begin{array}{l}\text { Cocaine } \\
\text { challenge }\end{array}$ & Basal & $\begin{array}{l}\text { Cocaine } \\
\text { challenge }\end{array}$ \\
\hline NAC dopamine & & & & \\
\hline NAC serotonin & & & & \\
\hline NAC glutamate & & & & \\
\hline PFC dopamine & - & - & 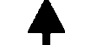 & - \\
\hline PFC serotonin & - & - & 1 & - \\
\hline PFC glutamate & - & - & - & - \\
\hline
\end{tabular}

NAC, nucleus accumbens; PFC, prefrontal cortex.

should be noted that the absolute/basal neurotransmitter levels provided here should be interpreted cautiously because they were determined in the absence of estimates of probe recovery or employment of no net flux procedures. Nevertheless, the pattern of neurochemical differences between naïve PNS and control rats may contribute to their differences in novelty- and cocaine-induced locomotor behavior. In particular, enhanced dopamine (basal and stimulated) and low basal with greater stimulated glutamate have been implicated in the sensitized locomotor response observed following repeated psychostimulant drug treatments (Heidbreder et al, 1996; Hooks et al, 1994; Kalivas and Duffy, 1993; Pierce et al, 1996; Reid and Berger, 1996; Szumlinski et al, 2006) and probably contribute to the presensitized behavioral responding of PNS rats. Further, serotonin inhibits dopamine (eg Rothman and Baumann, 2006) and glutamate (Szumlinski et al, 2004) transmission in the NAC. Thus, our observed reduction in overall serotonin levels in cocaine-naïve PNS rats could facilitate dopamine and glutamate in this region. In contrast, PNS rats with a history of cocaine treatment did not exhibit differences in basal dopamine and serotonin in the NAC but continued to exhibit lower basal glutamate and augmented cocaine-stimulated dopamine and glutamate transmission in the NAC. Further, cocaine-experienced, but not -naïve, PNS rats exhibited increased basal and enhanced cocainestimulated dopamine transmission in the PFC suggesting that PNS facilitates sensitization of mesocortical dopamine.

Our findings for NAC dopamine are consistent with previous reports of dopaminergic alterations following either PNS or prenatal glucocorticoid receptor agonist administration that include higher dopamine content and/ or higher dopamine metabolism (metabolite: neurotransmitter ratio) in striatal tissue, increased numbers of tyrosine hydroxylase-positive cells in the ventral tegmental area, and changes in NAC D2 and D3 receptor expression (eg Alonso et al, 1994; Barros et al, 2004; Berger et al, 2002; Diaz et al, 1995; Henry et al, 1995; McArthur et al, 2005). Moreover, the enhanced dopamine response to cocaine produced by PNS is similar to that reported in neonatal isolates (Kehoe et al, 1996; Kosten et al, 2004a, 2003, 2005, 2006; see also Howes et al, 2000 for similar results following juvenile isolation) or in rodents subjected to neonatal anoxia (Juarez et al, 2003) in response to other psychomotor stimulant drugs. Neonatal isolates also show a reduction in NAC serotonin (Kosten et al, 2004b) similar to that observed in the present study in PNS rats. Thus, as with the behavioral profiles produced by these early environmental insults, a presensitization of mesolimbic dopamine transmission may be a common neurochemical alteration produced by prenatal and early postnatal stress that endures into adulthood. Given the important role for NAC dopamine transmission in drug-seeking behavior (Anderson et al, 2003, 2006; Bachtell et al, 2005; Di Ciano et al, 2001; Neisewander et al, 1996; Ranaldi et al, 1999; Schmidt et al, 2006; Schmidt and Pierce, 2006), enhanced NAC dopamine responsiveness may contribute to the enhanced cocaineseeking observed in PNS rats.

PNS also enhanced cocaine-stimulated glutamate release in the NAC of both cocaine-naïve and -experienced rats. Moreover, PNS rats with a history of cocaine self-administration also exhibited significantly lower basal glutamate content, compared with cocaine-experienced controls. Decreased basal NAC glutamate levels and enhanced cocaine-stimulated glutamate release are neuroadaptations observed following repeated contingent or noncontingent cocaine administration (for reviews see Anderson and Pierce, 2005; Cornish and Kalivas, 2001; Vandershuren and Kalivas, 2000). PNS has been associated with increased NAC $N$-methyl-D-aspartate (NMDA) receptor expression (Barros et al, 2004; Berger et al, 2002), which are found presynaptically on corticostriatal terminals (Gracy and Pickel, 1996; Wang and Pickel, 2000). Given that the majority of cortical inputs to the striatum are glutamatergic, increased numbers of presynaptically localized NMDA receptors could result in glutamate enhancing its own release and contribute to the phenotype of PNS. With regards to cocaine-seeking, NAC glutamate levels rise during cocaine-primed reinstatement of cocaine-seeking behavior (McFarland et al, 2003), glutamate agonist infusion into the NAC can reinstate cocaine-seeking behavior (Cornish et al, 1999; Cornish and Kalivas, 2000), and glutamate antagonists attenuate cocaine-primed reinforcement (Cornish and Kalivas, 2000). Thus, a presensitization of dopamine, glutamate, or both within the NAC may mediate the higher level of motor-responsiveness to cocaine and cocaine-seeking behavior observed in PNS rats.

PNS also elevated PFC dopamine both before and after the cocaine challenge (with changes from baseline equivalent to controls), but this was observed only following selfadministration of cocaine, suggesting that early environmental insult predisposes this region to cocaine-induced neuroadaptations. Similar to findings in the NAC, there are alterations in dopamine D2 as well as NMDA and mGluRIII receptors in the PFC following PNS (Barros et al, 2004; Berger et al, 2002). Moreover, antagonism of dopamine D2 or D1 receptors in the PFC markedly attenuated cocaineprimed reinstatement of cocaine-seeking in both operant (Capriles et al, 2003; Sun and Rebec, 2005) and placeconditioned (Sanchez et al, 2003) models. Further, inactivation of the PFC blocks the rise in NAC glutamate necessary for cocaine-primed reinstatement (McFarland et al, 2003). 
Thus, the observed alterations in the mesocorticolimbic dopamine and glutamate are probably mediators of the PNS potentiation of cocaine-primed reinstatement of cocaineseeking behavior.

The factors that induce the behavioral and neurochemical alterations observed following PNS were not examined in the present study but appear to stem from both stress hormones produced during the PNS procedure and subsequent alterations in mother-pup interactions. There is extensive evidence that PNS procedures induce neuroendocrine responses in both dam and pup and that elevations in hormones can program the developing fetus, biasing it towards many diseases, including psychopathology (for recent reviews see Kapoor et al, 2006; Knackstedt et al, 2005; Koenig et al, 2005; Seckl and Meaney, 2006; Weinstock, 2005). On the other hand, growing evidence suggests that PNS-induced alterations are mediated, at least in part, by alterations in maternal interactions with offspring following birth (Smith et al, 2004; Neumann et al, 2005; Champagne and Meaney, 2006). Moreover, PNS rats raised by unstressed foster mothers show normalized glucocorticoid response to stress (Maccari et al, 1995) and normalized dopamine, glutamate, and $\gamma$-aminobutyric acid receptors throughout limbic circuits (Barros et al, 2004, 2006). However, adoption to unstressed mothers can produce similar or opposite effects in rats not exposed to PNS (Maccari et al, 1995; Barbazanges et al, 1996; Barros et al, 2004, 2006), suggesting that both the pre- and postnatal environments are important determinants of the adult's responsiveness to psychostimulant drugs. Future studies will need to determine which aspects of the behavioral and neurochemical abnormalities in cocaine responsiveness observed in PNS rats are due to alterations in neurodevelopment during gestation and which are produced or maintained during postnatal development.

The present study demonstrates that PNS induces enduring changes in the behavioral and mesocorticolimbic neurochemical response to cocaine and poses PNS as a useful model for understanding the neurobiological bases of addiction vulnerability to cocaine as well as other drugs of abuse. Specifically, we proposed that the enhanced dopamine and glutamate and reduced serotonin in the NAC contribute to the PNS enhancement in the psychomotor stimulant effects of cocaine. Moreover, our data indicates that enhanced dopamine in the PFC and NAC in combination with enhanced glutamate responsiveness in the NAC is associated with increased cocaine-seeking observed in PNS rats during cocaine-primed reinstatement. The ability of early environmental insult to alter mesocorticolimbic systems appears to make such individuals more responsive to psychostimulant drugs and, in particular, have a higher propensity to relapsing to drug-taking and thus more vulnerable to the persistent aspects of drug addiction.

\section{ACKNOWLEDGEMENTS}

This research was supported by National Institute on Drug Abuse Grants DA016511 (RES), DA015369 (RES), and DA021161 (TEK), NIH Grant C06 RR015455 (RES), NARSAD (TEK, KKS), and the Santa Barbara Cottage Hospital (TEK).

\section{DISCLOSURE/CONFLICT OF INTEREST}

There are no conflicts of interest for any of the authors relating to this paper. The following organizations have provided compensation for professional services to:

Tod E Kippin: Department of Psychology and The Neuroscience Research Institute, University of California at Santa Barbara and Department of Neurosciences, Medical University of South Carolina.

Karen K Szumlinski: Department of Psychology and The Neuroscience Research Institute, University of California at Santa Barbara and Department of Neurosciences, Medical University of South Carolina.

Zuzana Kapasova: Department of Psychology, University of California at Santa Barbara.

Betsy Rezner: Department of Psychology, University of California at Santa Barbara.

Ronald E See: Department of Neurosciences, Medical University of South Carolina.

\section{REFERENCES}

Alonso SJ, Navarro E, Rodriguez M (1994). Permanent dopaminergic alterations in then accumbens after prenatal stress. Pharmacol Biochem Behav 49: 353-358.

Anderson SM, Bari AA, Pierce RC (2003). Administration of the D1-like dopamine receptor antagonist SCH-23390 into the medial nucleus accumbens shell attenuates cocaine priminginduced reinstatement of drug-seeking behavior in rats. Psychopharmacology 168: 132-138.

Anderson SM, Pierce RC (2005). Cocaine-induced alterations in dopamine receptor signaling: implications for reinforcement and reinstatement. Pharmacol Ther 106: 389-403.

Anderson SM, Schmidt HD, Pierce RC (2006). Administration of the D2 dopamine receptor antagonist sulpiride into the shell, but not the core, of the nucleus accumbens attenuates cocaine priming-induced reinstatement of drug seeking. Neuropsychopharmacology 31: 1452-1461.

Bachtell RK, Whisler K, Karanian D, Self DW (2005). Effects of intra-nucleus accumbens shell administration of dopamine agonists and antagonists on cocaine-taking and cocaine-seeking behaviors in the rat. Psychopharmacology 183: 41-53.

Barbazanges A, Vallee M, Mayo W, Day J, Simon H, Le Moal M et al (1996). Early and later adoptions have different long-term effects on male rat offspring. J Neurosci 16: 7783-7790.

Barros VG, Berger MA, Martijena ID, Sarchi MI, Perez AA, Molina VA et al (2004). Early adoption modifies the effects of prenatal stress on dopamine and glutamate receptors in adult rat brain. J Neurosci Res 76: 488-496.

Barros VG, Rodriquez P, Martijena ID, Perez A, Molina VA, Antonelli MC et al (2006). Prenatal stress and early adoption effects on benzodiazepine receptors and anxiogenic behavior in the adult rat brain. Synapse 60: 609-618.

Berger MA, Barros VG, Sarchi MI, Tarazi FI, Antonelli MC (2002). Long-term effects of prenatal stress on dopamine and glutamate receptors in adult rat brain. Neurochem Res 27: 1525-1533.

Capriles N, Rodaros D, Sorge RE, Stewart J (2003). A role for the prefrontal cortex in stress- and cocaine-induced reinstatement of cocaine seeking in rats. Psychopharmacology 168: 66-74.

Champagne FA, Meaney MJ (2006). Stress during gestation alters postpartum maternal care and the development of the offspring in a rodent model. Biol Psychiatry 59: 1227-1235.

Cornish JL, Duffy P, Kalivas PW (1999). A role for nucleus accumbens glutamate transmission in the relapse to cocaineseeking behavior. Neuroscience 93: 1359-1367. 
Cornish JL, Kalivas PW (2000). Glutamate transmission in the nucleus accumbens mediates relapse in cocaine addiction. $J$ Neurosci 20: RC89.

Cornish JL, Kalivas PW (2001). Cocaine sensitization and craving: differing roles for dopamine and glutamate in the nucleus accumbens. J Addict Dis 20: 43-54.

Deminiere JM, Piazza PV, Guegan G, Abrous N, Maccari S, Le Moal $M$ et al (1992). Increased locomotor response to novelty and propensity to intravenous amphetamine self-administration in adult offspring of stressed mothers. Brain Res 586: 135-139.

Di Chiara G, Bassareo V, Fenu S, De Luca MA, Spina L, Cadoni C et al (2004). Dopamine and drug addiction: the nucleus accumbens shell connection. Neuropharmacology 4(Suppl 1): 22-24.

Di Ciano P, Blaha CD, Phillips AG (2001). Changes in dopamine efflux associated with extinction, CS-induced and d-amphetamine-induced reinstatement of drug-seeking behavior by rats. Behav Brain Res 120: 147-158.

Diaz R, Ogren SO, Blum M, Fuxe K (1995). Prenatal corticosterone increases spontaneous and $\mathrm{d}$-amphetamine induced locomotor activity and brain dopamine metabolism in prepubertal male and female rats. Neuroscience 66: 467-473.

Ferrario CR, Robinson TE (2006). Amphetamine pretreatment accelerates the subsequent escalation of cocaine self-administration behavior. Eur Neuropsychopharmacol 16: 352-357.

Gracy KN, Pickel VM (1996). Ultrastructural immunocytochemical localization of the $N$-methyl-D-aspartate receptor and tyrosine hydroxylase in the shell of the rat nucleus accumbens. Brain Res 739: 169-181.

Henry C, Guegant G, Cador M, Arnauld E, Arsaut J, Le Moal M et al (1995). Prenatal stress in rats facilitates amphetamineinduced sensitization and induces long-lasting changes in dopamine receptors in the nucleus accumbens. Brain Res 685: 179-186.

Heidbreder Ca, Thompson AC, Shippenberg TS (1996). Role of extracellular dopamine in the initiation and long-term expression of behavioral sensitization to cocaine. J Pharmacol Exp Ther 278: 490-502.

Hooks MS, Duffy P, Striplin C, Kalivas PW (1994). Behavioral and neurochemical sensitization following cocaine self-administration. Psychopharmacology 115: 265-272.

Howes SR, Dalley JW, Morrison CH, Robbins TW, Everitt BJ (2000). Leftward shift in the acquisition of cocaine selfadministration in isolation-reared rats: relationship to extracellular levels of dopamine, serotonin and glutamate in the nucleus accumbens and amygdala-striatal FOS expression. Psychopharmacology 151: 55-63.

Huizink AC, Mulder EJ, Buitelaar JK (2004). Prenatal stress and risk for psychopathology: specific effects or induction of general susceptibility? Psychol Bull 130: 115-142.

Juarez I, Silva-Gomez AB, Peralta F, Flores G (2003). Anoxia at birth induced hyperresponsiveness to amphetamine and stress in postpubertal rats. Brain Res 992: 281-287.

Kalivas PW, Duffy P (1993). Time course of extracellular dopamine and behavioral sensitization to cocaine. I. Dopamine axon terminals. J Neurosci 13: 266-275.

Kalivas PW, Volkow N, Seamans J (2005). Unmanageable motivation in addiction: a pathology in prefrontal-accumbens glutamate transmission. Neuron 45: 647-650.

Kapoor A, Dunn E, Kostaki A, Andrews MH, Mattews SG (2006). Fetal programming of hypothalamo-pituitary-adrenal function: prenatal stress and glucocorticoids. J Physiol 572: 31-44.

Kehoe P, Shoemaker WJ, Triano L, Hoffman J, Arons C (1996). Repeated isolation in the neonatal rat produces alterations in behavior and ventral striatal dopamine release in the juvenile after amphetamine challenge. Behav Neurosci 110: 1435-1444.

Kippin TE, Fuchs RA, See RE (2006). Contributions of prolonged contingent and noncontingent cocaine exposure to enhanced reinstatement of cocaine seeking in rats. Psychopharmacology 187: $60-67$.

Kippin TE, Fuchs RA, Mehta RH, Case JM, Parker MP, BimonteNelson HA et al (2005). Potentiation of cocaine-primed reinstatement of drug seeking in female rats during estrus. Psychopharmacology 182: 245-252.

Knackstedt MK, Hamelmann E, Arck PC (2005). Mothers in stress: consequences for the offspring. Am J Reprod Immunol 54: 63-69.

Koenig JI, Elmer GI, Shepard PD, Lee PR, Mayo C, Joy B et al (2005). Prenatal exposure to a repeated variable stress paradigm elicits behavioral and neuroendocrinological changes in the adult offspring: potential relevance to schizophrenia. Behav Brain Res 156: 251-261.

Kofman O (2002). The role of prenatal stress in the etiology of developmental behavioural disorders. Neurosci Biobehav Rev 26: 457-470.

Kosten TA, Miserendino MJ, Kehoe P (2000). Enhanced acquisition of cocaine self-administration in adult rats with neonatal isolation stress experience. Brain Res 875: 44-50.

Kosten TA, Sanchez H, Zhang XY, Kehoe P (2004a). Neonatal isolation enhances acquisition of cocaine self-administration and food responding in female rats. Behav Brain Res 151: 137-149.

Kosten TA, Zhang XY, Kehoe P (2003). Chronic neonatal isolation stress enhances cocaine-induced increases in ventral striatal dopamine levels in rat pups. Brain Res Dev Brain Res 141: 109-116.

Kosten TA, Zhang XY, Kehoe P (2004b). Infant rats with chronic neonatal isolation experience show decreased extracellular serotonin levels in ventral striatum at baseline and in response to cocaine. Brain Res Dev Brain Res 152: 19-24.

Kosten TA, Zhang XY, Kehoe P (2005). Neurochemical and behavioral responses to cocaine in adult male rats with neonatal isolation experience. J Pharmacol Exp Ther 314: 661-667.

Kosten TA, Zhang XY, Kehoe P (2006). Heightened cocaine and food self-administration in female rats with neonatal isolation experience. Neuropsychopharmacology 31: 70-76.

Lominac KD, Kapasova Z, Hannun RA, Patterson C, Middaugh LD, Szumlinski KK (2006). Behavioral and neurochemical interactions between Group $1 \mathrm{mGluR}$ antagonists and ethanol: potential insight into their anti-addictive properties. Drug Alcohol Depend 85: $142-156$

Lynch WJ, Mangini LD, Taylor JR (2005). Neonatal isolation stress potentiates cocaine seeking behavior in adult male and female rats. Neuropsychopharmacology 30: 322-329.

Maccari S, Piazz PV, Kabbaj M, Barbazanges A, Simon H, Le Moal $M$ (1995). Adoption reverses the long-term impairment in glucocorticoid feedback induced by prenatal stress. J Neurosci 15: $100-106$.

Marquardt AR, Ortiz-Lemos L, Lucion AB, Barros HM (2004). Influence of handling or aversive stimulation during rats' neonatal or adolescence periods on oral cocaine self-administration and cocaine withdrawal. Behav Pharmacol 15: 403-412.

Matthews K, Robbins TW, Everitt BJ, Caine SB (1999). Repeated neonatal maternal separation alters intravenous cocaine selfadministration in adult rats. Psychopharmacology 141: 123-134.

McArthur S, McHale E, Dalley JW, Buckingham JC, Gillies GE (2005). Altered mesencephalic dopaminergic populations in adulthood as a consequence of brief perinatal glucocorticoid exposure. J Neuroendocrinol 17: 475-482.

McFarland K, Davidge SB, Lapish CC, Kalivas PW (2004). Limbic and motor circuitry underlying footshock-induced reinstatement of cocaine-seeking behavior. J Neurosci 24: 1551-1560.

McFarland K, Lapish CC, Kalivas PW (2003). Prefrontal glutamate release into the core of the nucleus accumbens mediates cocaineinduced reinstatement of drug-seeking behavior. J Neurosci 23: $3531-3537$ 
Neisewander JL, O’Dell LE, Tran-Nguyen LT, Castaneda E, Fuchs RA (1996). Dopamine overflow in the nucleus accumbens during extinction and reinstatement of cocaine self-administration behavior. Neuropsychopharmacology 15: 506-514.

Neumann ID, Kromer SA, Bosch OJ (2005). Effects of psycho-social stress during pregnancy on neuroendocrine and behavioural parameters in lactation depend on the genetically determined stress vulnerability. Psychoneuroendocrinology 30: 791-806.

Paxinos G, Watson C (1986). The Rat Brain in Sterotaxic Corrdinates, 2nd edn. Academic Press: Orlando, FL.

Pierce RC, Bell K, Duffy P, Kalivas PW (1996). Repeated cocaine augments excitatory amino acid transmission in the nucleus accumbens only in rats having developed behavioral sensitization. J Neurosci 16: 1550-1560.

Ranaldi R, Pocock D, Zereik R, Wise RA (1999). Dopamine fluctuations in the nucleus accumbens during maintenance, extinction, and reinstatement of intravenous $\mathrm{D}$-amphetamine self-administration. J Neurosci 19: 4102-4109.

Reid MS, Berger SP (1996). Evidence for sensitization of cocaineinduced nucleus accumbens glutamate release. Neuroreport 7: 1325-1329.

Rothman RB, Baumann MH (2006). Balance between dopamine and serotonin release modulates behavioral effects of amphetamine-type drugs. Ann NY Acad Sci 1074: 245-260.

Sanchez CJ, Bailie TM, Wu WR, Li N, Sorg BA (2003). Manipulation of dopamine d1-like receptor activation in the rat medial prefrontal cortex alters stress- and cocaine-induced reinstatement of conditioned place preference behavior. Neuroscience 119: 497-505.

Schmidt HD, Anderson SM, Pierce RC (2006). Stimulation of D1-like or D2 dopamine receptors in the shell, but not the core, of the nucleus accumbens reinstates cocaine-seeking behaviour in the rat. Eur J Neurosci 23: 219-228.

Schmidt HD, Pierce RC (2006). Cooperative activation of D1-like and D2-like dopamine receptors in the nucleus accumbens shell is required for the reinstatement of cocaine-seeking behavior in the rat. Neuroscience 142: 451-461.

Seckl JR, Meaney MJ (2006). Glucocorticoid 'programming' and PTSD risk. Ann NY Acad Sci 1071: 351-378.

Smith JW, Seckly JR, Evans AT, Costall B, Smythe JW (2004). Gestational stress induces post-partum depression-like behaviour and alters maternal care in rats. Psychoneuroendocrinology 29: 227-244.

Sun W, Rebec GV (2005). The role of prefrontal cortex D1-like and D2-like receptors in cocaine-seeking behavior in rats. Psychopharmacology 177: 315-323.
Suto N, Austin JD, Tanabe LM, Kramer MK, Wright DA, Vezina P (2002). Previous exposure to VTA amphetamine enhances cocaine self-administration under a progressive ratio schedule in a D1 dopamine receptor dependent manner. Neuropsychopharmacology 27: 970-979.

Suto N, Tanabe LM, Austin JD, Creekmore E, Vezina P (2003). Previous exposure to VTA amphetamine enhances cocaine selfadministration under a progressive ratio schedule in an NMDA, AMPA/kainate, and metabotropic glutamate receptor-dependent manner. Neuropsychopharmacology 28: 629-639.

Szumlinski KK, Abernathy KE, Oleson EB, Klugmann M, Lominac $\mathrm{KD}, \mathrm{He} \mathrm{DY}$ et al (2006). Homer isoforms differentially regulate cocaine-induced neuroplasticity. Neuropsychopharmacology 31: 768-777.

Szumlinski KK, Diab ME, Friedman R, Henze LM, Lominac KD, Bowers MS (2007). Accumbens neurochemical adaptations produced by binge-like alcohol consumption. Psychopharmaco$\log y$ 190: 415-431.

Szumlinski KK, Frys KA, Kalivas PW (2004). Dissociable roles for the dorsal and median raphe in the facilitatory effect of 5-HT1A receptor stimulation upon cocaine-induced locomotion and sensitization. Neuropsychopharmacology 29: 1675-1687.

Vallee M, Mayo W, Dellu F, Le Moal M, Simon H, Maccari S (1997). Prenatal stress induces high anxiety and postnatal handling induces low anxiety in adult offspring: correlation with stressinduced corticosterone secretion. J Neurosci 17: 2626-2636.

Vandershuren LJ, Kalivas PW (2000). Alterations in dopaminergic and glutamatergic transmission in the induction and expression of behavioral sensitization: a critical review of preclinical studies. Psychopharmacology 151: 99-120.

Wang H, Pickel VM (2000). Presence of NMDA-type glutamate receptors in cingulate corticostriatal terminals and their postsynaptic targets. Synapse 35: 300-310.

Weinstock M (2001). Alterations induced by gestational stress in brain morphology and behaviour of the offspring. Prog Neurobiol 65: 427-451.

Weinstock M (2005). The potential influence of maternal stress hormones on development and mental health of the offspring. Brain Behav Immun 19: 296-308.

Welberg LA, Seckl JR (2001). Prenatal stress, glucocorticoids and the programming of the brain. J Neuroendocrinol 13: $113-128$.

Zhang XY, Sanchez H, Kehoe P, Kosten TA (2005). Neonatal isolation enhances maintenance but not reinstatement of cocaine self-administration in adult male rats. Psychopharmacology 177: 391-399. 